J. Lake Sci.(湖泊科学), 2008, 20(6): 790-795

http://www.jlakes.org. E-mail: jlakes@niglas.ac.cn

(C)2008 by Journal of Lake Sciences

\title{
东太湖水生植物及其与环境的相互作用*
}

\author{
何 俊 ${ }^{1,2}$, 谷孝鸿 ${ }^{1 * *}$, 刘国锋 ${ }^{1,2}$ \\ (1: 中国科学院南京地理与湖泊研究所湖泊与环境国家重点实验室，南京 210008) \\ (2: 中国科学院研究生院，北京 100049)
}

摘 要: 2006-2007 年对东太湖网围养殖区及航道水生植物种群结构和水环境状况进行了调查. 结果表明: 采样区内共有水生 植物 10 种, 其中沉水植物 6 种、浮叶植物 3 种、漂浮植物 1 种; 养殖区植物种类较单一, 耐污染、再生能力强以及水质净化 能力好的金鱼藻、狐尾藻和伊乐藻在养殖区呈优势种分布; 航道和敞水区优势种类为苦草和马来眼子菜. 从水生植物生物量 变化来看, 9 月生物量最高, 平均为 $2882.4 \pm 748.8 \mathrm{~g} / \mathrm{m}^{2}$; 养殖区水生植物生物量高于航道和敞水区, 两个网区平均可达 $1251.2 \pm 1012.7 \mathrm{~g} / \mathrm{m}^{2} 、 993.9 \pm 968.6 \mathrm{~g} / \mathrm{m}^{2}$. 水生植物与水环境相互关系来看, 温度、透明度和 $\mathrm{pH}$ 等水体物理环境因子对水生植物 季节生长和光合作用具有重要影响; 水生植物具有吸收水体氮磷营养盐和抑制藻类生长的作用，从而改善了东太湖水质，同 时植物季节性生长以及空间分布差异也影响水质时空差异.

关键词: 东太湖; 水生植物; 水环境

\section{Aquatic macrophytes in East Lake Taihu and its interaction with water environment}

\author{
HE Jun ${ }^{1,2}$, GU Xiaohong ${ }^{1} \&$ LIU Guofeng ${ }^{1,2}$ \\ (1: State Key Laboratory of Lake Science and Environment, Nanjing Institute of Geography and Limnology, Chinese Academy of \\ Sciences, Nanjing 210008, P.R.China) \\ (2: Graduate School of the Chinese Academy of Sciences, Beijing 100049, P.R.China)
}

\begin{abstract}
The aquatic macrophytes and water environments in the enclosure aquaculture area and waterway of East Lake Taihu were investigated during 2006 and 2007. The results showed that there were ten species of aquatic macrophytes in the investigated area, among six submerged macrophytes, three emergent plants and one floating plant. The plant species were dominant by Ceratophyllum demersum, Myriophyllum spicatum and Elodea nuttalli in the enclosure aquaculture area, which are pollutant-resistant, regeneration-strong and purification-good macrophytes, while Potamogeton malaianus and Vallisneria spiralis were the dominant species both in the waterway and open water region. Aquatic macrophytes grew vigorously between summer and autumn and the maximum macrophyte biomass was in September when it could reach to $2882.4 \pm 748.8 \mathrm{~g} / \mathrm{m}^{2}$. The biomasses of macrophyte in two enclosure aquaculture areas were $1251.2 \pm 1012.7 \mathrm{~g} / \mathrm{m}^{2}$ and $993.9 \pm 968.6 \mathrm{~g} / \mathrm{m}^{2}$, respectively, which were higher biomass than other water area. The physical factors in water, such as temperature, transparency and $\mathrm{pH}$, had important influences on photosynthesis and seasonal growth of aquatic macrophytes. Through absorption of nitrogen and phosphorus nutrients and inhibition of algae growth by aquatic macrophyte in the water body, the water quality of East Lake Taihu had been improved. The patterns of aquatic macrophyte in the lake could also affect the temporal-spatial difference of water quality.

Keywords: East Lake Taihu; aquatic macrophytes; water environment
\end{abstract}

湖泊水生植物不仅是湖泊渔业的主要天然饵料, 也是湖泊生态系统演化和湖泊生态平衡的重要调控

* 中国科学院农业创新基地项目“浅水湖泊环保型渔业资源可持续利用及示范”和江苏省太湖渔业管理委员会重点项目“太 湖生物资源结构与有效保护利用研究”联合资助. 2008-01-04收稿; 2008-07-09 收修改稿. 何俊, 女, 1982年生, 硕士研 究生; E-mail: jhe@niglas.ac.cn.

** 通讯作者; E-mail: xhgu @niglas.ac.cn. 
者 ${ }^{[1-2]}$. 随着地区经济发展和水环境污染程度的加剧, 一方面我国湖泊特别是长江中下游的许多湖泊出现 严重的藻型富营养化，水生植物面积不断萎缩，个别种类不断减少甚至消失，水质恶化 ${ }^{[3]}$; 另一方面，对 于一些草型浅水湖泊, 由于湖泊渔业结构的调整和改变, 水生植物群落结构演替剧烈, 湖泊沼泽化加剧 ${ }^{[4-5]}$. 东太湖位于太湖东南隅 $\left(30^{\circ} 58^{\prime}-31^{\circ} 07^{\prime} \mathrm{N} ; 120^{\circ} 25^{\prime}-120^{\circ} 35^{\prime} \mathrm{E}\right)$, 与西太湖之间以狭窄的湖面相通, 总长 度 $27.5 \mathrm{~km}$, 最大宽度 $9.0 \mathrm{~km}$, 总面积 $131 \mathrm{~km}^{2}$, 平均水深不到 $1.2 \mathrm{~m}$, 湖区内生长着繁茂的水生植物, 是长 江中下游典型的草型浅水湖泊 ${ }^{[6]}$. 本文在调查基础上, 研究了东太湖水生植物种类组成和空间分布及其 与水环境的相互作用, 以期为湖泊水生植物资源合理开发利用提供科学依据.

\section{1 研究方法}

\section{1 采样点布置}

根据东太湖功能及不同利用方式的区域,于2006年9、11月, 2007年1、3、5、6、7、8月每月中下旬，共 8次, 沿东太湖东荠咀至大缺港的方向, 分别在网围 养殖区和航道设置 6 个采样点 (图1). 其中 $1^{\#}$ 和 $4^{\#}$ 点 设在养殖密度不同的网围区内; $2^{\#}$ 点位于东荠咀的 航道; $3^{\#}$ 点设在 $4^{\#}$ 点所在养殖区附近航道上; $5^{\#}$ 点 设在敞水区主航道; $6^{\#}$ 点位于大缺港附近的航道.

\section{2 水生植物采样方法和测定}

使用自行研制的刀片，长为 $0.30 \mathrm{~m}$ 的水草采集 刀, 旋转一周, 采集 $0.28 \mathrm{~m}^{2}$ 圆面积的水生植物地上 部分. 为将植物种类采集完全, 在同一采样点采集 2 次, 样品采集后立即用湖水清洗去泥, 装入样品袋 内. 在室内取出袋内植物, 去除枯枝、败叶和其他 杂质; 去除植物体表多余的水分, 按种类称其鲜重. 求出两次采集样品的重量平均值, 并计算单位面 积植物鲜重, 从而得出该点植物生物量. 受采样条 件限制，本次调查不涉及挺水植物的调查.

\section{3 水质测试项目和分析方法}

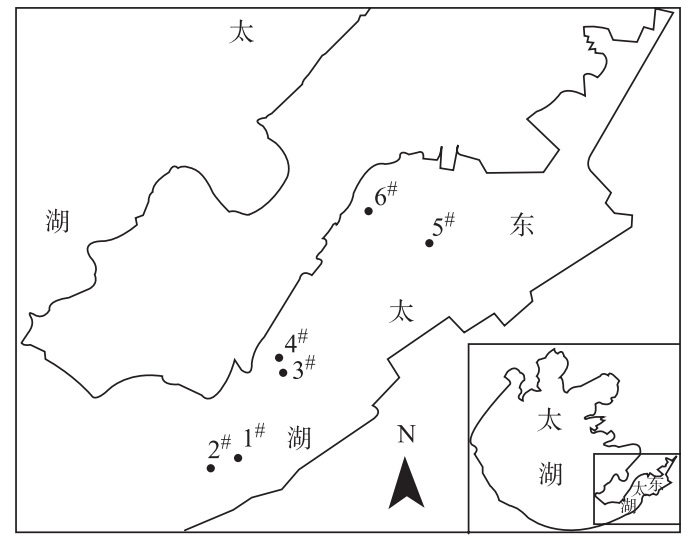

图 1 东太湖水环境调查采样点示意图

Fig.1 Sketch map for Location of the sampling sites in East Lake Taihu

采集表底层混合水样进行理化分析，测定参数有：水深、水温、透明度、 $\mathrm{pH}$ 值、总氮(TN)、总磷(TP)、 叶绿素(Chl.a). 样品分析方法参照《湖泊富营养化调查规范》 ${ }^{[7]}$ 进行.

\section{2 结果与分析}

\section{1 水生植物种类组成及空间分布}

在设定的采样区共采集到水生植物 10 种, 其中沉水植物 6 种、浮叶植物 3 种、漂浮植物 1 种(表 1 ). 根据水生植物分布可知, 沉水植物是东太湖的优势植物类群, 其中养殖区优势种为金鱼藻、穗花狐尾藻 和伊乐藻; 航道和敞水区优势种类为苦草、马来眼子菜. 养殖区水生植物种类较单一, 航道和敞水区种类 较丰富.

\section{2 水生植物生物量及其变化}

从水生植物生物量季节变化来看(图 2a), 9 月水生植物生物量最高, 平均可达 $2882.4 \pm 748.8 \mathrm{~g} / \mathrm{m}^{2} ; 9$ 月 以后开始出现衰败至死亡, 冬季 1 月植物生物量最低, 平均仅为 $83.09 \pm 138.2 \mathrm{~g} / \mathrm{m}^{2}$, 春季 3 月植物开始生长, 至夏季生物量呈增长的态势. 从水生植物生物量空间分布来看(图 $2 \mathrm{~b}), 1^{\#}$ 和 $4^{\#}$ 网围区水生植物生物量较 高, 平均生物量分别为 $1251.2 \pm 1012.7 \mathrm{~g} / \mathrm{m}^{2} 、 993.9 \pm 968.6 \mathrm{~g} / \mathrm{m}^{2}$, 养殖旺季 $(5 、 6 、 7 、 8 、 9$ 月)两个网围区内 金鱼藻呈优势种分布. 各航道水生植物生物量较接近, 平均为 $576.85 \pm 917.32 \mathrm{~g} / \mathrm{m}^{2}$, 苦草在各航道呈优势 种分布， 9 月 $2^{\#} 、 3^{\#} 、 5^{\#}$ 和 $6^{\#}$ 点苦草占总生物量比例分别为 $100 \% 、 80 \% 、 100 \%$ 和 $40 \%$. 
表 1 各采样点水生植物种类组成 ${ }^{*}$

Tab.1 Species of aquatic macrophytes occurring of the sampling sites

\begin{tabular}{|c|c|c|c|c|c|c|c|}
\hline \multirow{2}{*}{ 生态型 } & \multirow{2}{*}{ 水生植物种类 } & \multicolumn{6}{|c|}{ 采样点 } \\
\hline & & $1^{\#}$ & $2^{\#}$ & $3^{\#}$ & $4^{\#}$ & $5^{\#}$ & $6^{\#}$ \\
\hline \multirow[t]{6}{*}{ 沉水植物 } & 金鱼藻(Ceratophyllum demersum) & ++ & + & ++ & ++ & + & + \\
\hline & 穗花狐尾藻(Myriophyllum spicatum) & ++ & & + & ++ & + & \\
\hline & 苦草(Vallisneria spiralis) & & ++ & ++ & & ++ & ++ \\
\hline & 马来眼子菜(Potamogeton malaianus) & & ++ & + & & ++ & + \\
\hline & 轮叶黑藻(Hydrilla verticillata) & & + & + & & + & + \\
\hline & 伊乐藻(Elodea nuttalli) & ++ & + & + & ++ & + & + \\
\hline \multirow[t]{2}{*}{ 浮叶植物 } & 苦菜(Limnanthemum nymphoides) & & & & & & + \\
\hline & 菱(Trapa maximowiczii) & & & & & & + \\
\hline \multirow[t]{2}{*}{ 漂浮植物 } & 水鳖 $($ Hydrocharis dubia) & + & & & + & & \\
\hline & 紫背浮萍(Spirodela polyrhiza) & + & & & + & & \\
\hline
\end{tabular}

*“+”表示出现; “++”表示优势种.
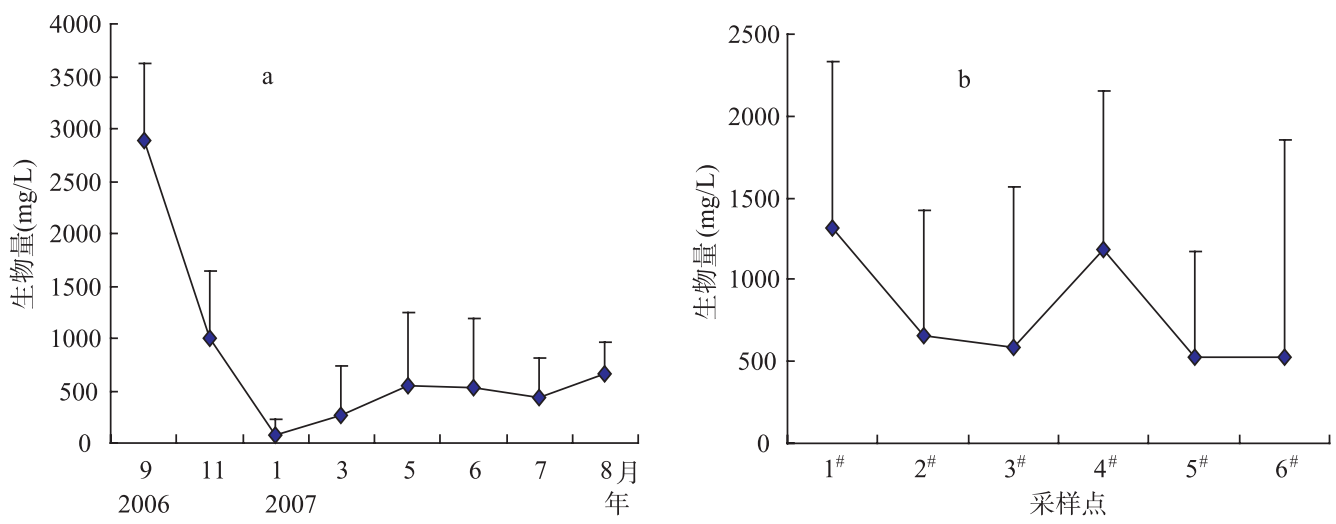

图 2 水生植物生物量时空变化(a: 月变化; b: 空间变化)

Fig.2 Temporal and spatial change of aquatic macrophytes biomass (a: monthly change; b: spatial change)

表 2 水体物理化学指标变动

Tab.2 The variation of physical and chemical parameter in East Lake Taihu

\begin{tabular}{cccccccc}
\hline 月份 & $\begin{array}{c}\text { 水温 } \\
\left({ }^{\circ} \mathrm{C}\right)\end{array}$ & $\begin{array}{c}\text { 水深 } \\
(\mathrm{m})\end{array}$ & $\begin{array}{c}\text { 透明度 } \\
(\mathrm{m})\end{array}$ & $\mathrm{pH}$ 值 & $\begin{array}{c}\text { 总氮 } \\
(\mathrm{mg} / \mathrm{L})\end{array}$ & $\begin{array}{c}\text { 总磷 } \\
(\mathrm{mg} / \mathrm{L})\end{array}$ & $\begin{array}{c}\text { 叶绿素 } \\
(\mu \mathrm{g} / \mathrm{L})\end{array}$ \\
\hline 9 & $22.73 \pm 0.42$ & $1.78 \pm 0.29$ & $0.66 \pm 0.20$ & $7.84 \pm 0.20$ & $1.40 \pm 0.31$ & $0.04 \pm 0.01$ & $5.35 \pm 3.06$ \\
11 & $9.92 \pm 0.19$ & $1.25 \pm 0.26$ & $0.75 \pm 0.06$ & $7.73 \pm 0.05$ & $1.40 \pm 0.35$ & $0.07 \pm 0.05$ & $2.26 \pm 0.95$ \\
1 & $5.33 \pm 0.41$ & $1.18 \pm 0.25$ & $1.00 \pm 0.21$ & $7.76 \pm 0.11$ & $1.81 \pm 0.29$ & $0.08 \pm 0.09$ & $7.05 \pm 2.06$ \\
3 & $13.67 \pm 0.75$ & $0.89 \pm 0.19$ & $0.39 \pm 0.32$ & $8.08 \pm 0.37$ & $1.85 \pm 1.11$ & $0.06 \pm 0.04$ & $11.63 \pm 4.90$ \\
5 & $25.33 \pm 0.74$ & $0.89 \pm 0.27$ & $0.68 \pm 0.26$ & $8.29 \pm 0.24$ & $1.12 \pm 0.32$ & $0.07 \pm 0.02$ & $4.49 \pm 2.07$ \\
6 & $30.39 \pm 0.56$ & $1.03 \pm 0.31$ & $0.88 \pm 0.26$ & $7.38 \pm 0.21$ & $0.98 \pm 0.11$ & $0.04 \pm 0.02$ & $6.47 \pm 3.99$ \\
7 & $32.28 \pm 0.44$ & $1.39 \pm 0.20$ & $1.13 \pm 0.36$ & $7.89 \pm 0.22$ & $1.25 \pm 0.10$ & $0.05 \pm 0.02$ & $10.53 \pm 7.57$ \\
8 & $28.97 \pm 0.67$ & $1.25 \pm 0.29$ & $1.06 \pm 0.31$ & $6.95 \pm 0.33$ & $1.27 \pm 0.28$ & $0.06 \pm 0.03$ & $3.57 \pm 3.91$ \\
平均 & $21.08 \pm 9.62$ & $1.21 \pm 0.37$ & $0.82 \pm 0.34$ & $7.74 \pm 0.45$ & $1.38 \pm 0.52$ & $0.06 \pm 0.04$ & $6.42 \pm 4.85$ \\
\hline
\end{tabular}




\section{3 水体理化指标的变动}

东太湖平均水温最高出现在 7 月, 为 $32.28 \pm 0.44^{\circ} \mathrm{C}$, 最低出现在 1 月, 为 $5.33 \pm 0.41^{\circ} \mathrm{C}$ (表 2 ). 水体透明 度平均为 $0.82 \pm 0.34 \mathrm{~m}$, 透明度可占平均水深的 $67.8 \%$. 季节变化来看, 夏秋季透明度高于冬春季; 点位变化 来看, 网围养殖区和敞水区透明度高于航道, 其中 $6^{\#}$ 点所在航道透明度最低, 平均为 $0.49 \pm 0.22 \mathrm{~m} . \mathrm{pH}$ 平均 为 7.74 \pm 0.45 , 春季 $(3 、 5$ 月 $) \mathrm{pH}$ 多超过 8.0 ; 夏季和秋冬季 $\mathrm{pH}$ 在 7.8 左右 ; 各月点位差异不是很显著. 水体 $\mathrm{TN}$ 平均为 $1.38 \pm 0.52 \mathrm{mg} / \mathrm{L}, \mathrm{TP}$ 平均为 $0.06 \pm 0.04 \mathrm{mg} / \mathrm{L}$. TN、TP 夏秋季低于冬春季; $\mathrm{TN} 、 \mathrm{TP} 6^{\#}$ 点最高, 平 均为 $1.71 \pm 0.76 \mathrm{mg} / \mathrm{L} 、 0.12 \pm 0.08 \mathrm{mg} / \mathrm{L}$, 分别比敞水区高 $18.1 \% 、 53.9 \% ; 2^{\#} 、 3^{\#}$ 航道高于附近网围区，与 敞水区接近. 叶绿素平均浓度为 $6.42 \pm 4.85 \mu \mathrm{g} / \mathrm{L}$, 在 3 和 7 月出现两个峰值, 分别为 $11.63 \pm 4.90 \mu \mathrm{g} / \mathrm{L}$ 、 $10.53 \pm 7.57 \mu \mathrm{g} / \mathrm{L} .3$ 月 $2^{\#} 、 6^{\#}$ 点 Chl.a 最高, 分别达 $17.30 \mu \mathrm{g} / \mathrm{L} 、 16.74 \mu \mathrm{g} / \mathrm{L} ; 7$ 月 $4^{\#} 、 5^{\#}$ 点较高, 两点分别 达 $19 \mu \mathrm{g} / \mathrm{L} 、 21.2 \mu \mathrm{g} / \mathrm{L}$.

\section{3 讨论}

\section{1 水生植物与水体物理因子的相互作用}

温度是影响植物季节生长的重要环境因子 ${ }^{[8-9]}$. 春季苦草开始萌发, 且随气温上升开始缓慢生长, 夏 季为快速生长期, 最大生物量出现在 9 月, 9月 $2^{\#}$ 航道内苦草生物量可达 $2255.5 \mathrm{~g} / \mathrm{m}^{2}$, 至 11 月生物量逐渐减 少, 冬季地上部分开始死亡. 伊乐藻在水温 $5-30^{\circ} \mathrm{C}$ 都能处于正常的生长状态, 最适温度为 $25^{\circ} \mathrm{C}$ 左右, $30^{\circ} \mathrm{C}$ 以上对其生长有抑制 ${ }^{[10]}$. 东太湖 5-6月为伊乐藻生长高峰期，6月 $4^{\#}$ 养殖区伊乐藻生物量占总生物量比例 达 $45 \%$ 左右，进人 7 月高温期生长开始停滞并进人休眠状态. 秋季再度生长, 形成新的种群. 可利用光能 是影响水生植物丰度和分布的重要因素, 光照条件与水体透明度直接相关 ${ }^{[11-12]}$. 东太湖水体透明度较高, 透明度可占平均水深的 $67.8 \%$, 光补偿深度超过水深, 说明有相当的太阳光线可投射到湖底层, 这为水生 植物的生长发育提供了充足的光源. 水体良好的透明度条件也使得东太湖成为太湖大型水生植物主要分 布区域之一 ${ }^{[13]}$. 同时, 水生植物季节生长也影响水体透明度的变化, 夏秋季, 水生植物生长旺盛, 水体中 颗粒物质被水生植物吸附、截留等而沉降除去, 从而水体透明度升高; 而在冬季, 水生植物生命活动停滞, 植物叶片吸收颗粒物的能力降低, 透明度也随之下降. $\mathrm{pH}$ 值将直接影响水体中无机碳源的存在形式, 进 而影响到水生植物光和作用速率 ${ }^{[14]}$. 水生植物最易利用的无机碳源形式是 $\mathrm{CO}_{2}$, 但在碱性环境下, 一些 沉水植物对 $\mathrm{HCO}_{3}{ }^{-}$或 $\mathrm{CO}_{3}{ }^{2-}$ 仍具有较强的利用能力, 这体现了水生植物具有适应环境胁迫的可塑性 ${ }^{[15]}$. 东 太湖水体 $\mathrm{pH}$ 值大小基本位于 7-8之间, 最高可达 $8.29 \pm 0.24$, 说明水体处于中性偏碱水平, 而水生植物在 东太湖能较好地生长, 说明这些水生植物具有较强的耐受 $\mathrm{pH}$ 的能力 ${ }^{[16-19]}$.

\section{2 水生植物对水体营养盐吸收和藻类抑制作用}

水生植物生长的季节性规律影响其对水体氮磷营养盐的吸收，东太湖氮磷营养盐季节变化呈现春 冬季积累, 夏秋季消耗的特征. 这与各季节内水生植物净化效能的差异、人类活动干扰及温度、水量、 风向风速等环境因子的变化等有关 ${ }^{[20]}$. 氮磷营养盐点位比较来看, 养殖区营养盐浓度较低. 养殖区虽大 量投饵以及河蟹活动能带来较多污染物质, 但经过湖水的大量稀释作用和养殖区内优质水生植物伊乐藻 等强大的吸收净化效能, 使得养殖区营养盐含量减少; 其次一部分营养盐以有机碎屑的形式沉积于底泥 或被螺蚬等底栖动物所利用从而脱离水体 ${ }^{[21]}$. 吴庆龙等的研究结果也表明, 草型湖泊网围养蟹对水质影 响不是很明显 ${ }^{[22]}$. 对各月水生植物生物量和叶绿素含量作相关性分析, 得出两者间的关系式为: $y=$ $-0.0013 x+7.44\left(R^{2}=0.1192\right)$, 表明两者呈负相关性. 水生植物由于个体大、生命周期长、吸附和储存营养 盐能力强, 能够通过对光环境和营养盐竞争, 以及为食浮游植物的浮游动物提供避难场所和分泌化感物 质来抑制藻类生长 ${ }^{[23-24]}$. 东太湖由于水生植物对藻类的抑制作用也使得东太湖水体叶绿素含量较太湖其 他湖区低 ${ }^{[20]}$.

\section{3 人类活动对水生植物及水环境的影响}

从水生植物空间分布来看, 金鱼藻、穗花狐尾藻和伊乐藻在两个养殖区均呈优势种分布. $1^{\#}$ 养殖区原 本是苦草分布区，网围养蟹以后，由于河蟹在摄食过程中从根部咬断沉水植物，导致植株漂起，不利于 低生长点植物一苦草的生长 ${ }^{[25]}$, 使得新围的苦草区续养第二年就被河蟹摄食殆尽. 其次, 4月幼蟹已从 
暂养箱放出, 苦草新生嫩芽容易被摄食, 因此养殖户不选用苦草喂养河蟹. 伊乐藻是一种速生高产、营 养丰富的沉水植物，同时还具有较强的水质净化能力，从而广受养殖户欢迎 ${ }^{[26]}$. 网围具有阻滞风浪和水 流的作用, 这不利于污染物的扩散, 并减轻了网围周围的风浪冲刷强度, 有利于金鱼藻、狐尾藻等这类喜 静态环境、耐污染、再生能力强的水生植物在养殖区的生长 ${ }^{[27-28]}$. 由于网围的通透性和水体流动性, 网 围养殖产生的污染物随水流向外扩散，从而对网围周围的水质和水生植物产生了一定的影响 ${ }^{[29]} \cdot 3^{\#}$ 航 道两侧均为网围区, 水体流动性较小, 同时受网围内污染物扩散影响, 喜静水、耐污染的水生植物如金鱼 藻在此形成优势种, 并且网围内扩散出的污染物也为水绵生长提供了较好的营养条件. 从东太湖目前的 养殖布局分析, 网围几乎分割并包围了整个湖面, 严重妨碍了对水草的收割, 植株腐烂沉积, 将加速东 太湖，尤其是沿岸区域的淤浅和沼泽化过程; 同时河蟹选择性摄食以及人为耙捞水草做河蟹饲料，使得 网围周围以及被耙过的水草区没有饲用价值的水生植物如苦菜、野菱、水鳖等大量生长,植株自然腐烂 分解将消耗水体溶解氧, 释放 $\mathrm{H}_{2} \mathrm{~S}$ 等有毒物质, 最终将影响湖泊水质 ${ }^{[30]}$.

喜流水、耐浊、抗风浪的苦草和马来眼子菜在 $2^{\#}$ 航道形成优势种, $2^{\#}$ 航道位于西太湖南部与东太湖交 界处, 受西太湖浑浊水流影响水体较混浊、流动性大, 非常适合这两种水生植物的生长; 同时 $2^{\#}$ 航道也 是东太湖水生植物保护区, 水生植物在此生长较好. $5^{\#}$ 航道位于东太湖敞水区, 人类活动影响较小, 维持 了较丰富的水生植物种类和较良好的水质. $6^{\#}$ 航道位于大缺港附近, 水位较浅, 由于人工清淤等原因导致 底质较硬, 再加上人为耙草、船只螺旋桨对水生植物底泥以上部分的绞杀等原因, 使得水生植物种类减 少; 同时 $6^{\#}$ 航道受东山半岛外源污染物排放影响以及渔船行驶扰动作用, 致使水体透明度较低, 水体氮 磷含量较高, 水质较差.

\section{4 结论}

(1)在设定的采样区共采集到水生植物 10 种, 其中沉水植物 6 种、浮叶植物 3 种、漂浮植物 1 种. 分 析表明, 水体物理环境因子温度、透明度和 $\mathrm{pH}$ 等对水生植物季节生长和光合作用具有重要影响; 水生植 物通过吸收水体 $\mathrm{N} 、 \mathrm{P}$ 营养盐和抑制藻类生长改善了水质，同时植物季节性生长以及空间分布差异也影 响水质时空差异.

(2)人类活动对东太湖水生植物以及水环境均产生重要影响. 网围养殖活动使得养殖区内水生植物种 类较单一, 耐污染、再生能力强以及水质净化能力好的金鱼藻、狐尾藻和伊乐藻在养殖区呈优势种分布; 养殖区内污染物的扩散，也影响网围周围水质及水生植物分布; 除此之外，渔船行驶，航道疏浚清淤以 及西太湖混浊来水也影响了航道水生植物的生长和分布.

(3)由于过度网围对水草收割产生影响, 并引起水生植被退化, 将加速东太湖的沼泽化和水质的恶化. 因此，必须合理规划网围养殖面积和布局，防止全湖和局部性环境和植被的退化.

\section{5 参考文献}

[1] Ozimek T, Gulati RD, Van DE. Can macrophytes be useful in bio-manipulation of Lake? The lake Zwemulust example. Hydrobiologia, 1990, 200/201: 399-409.

[2] Engel S. The role and interaction of submerged macrophytes in a shallow Wisconsin Lake. Journal of FreshwaterEcology, 1998, 4: 329-341.

[3] 于 丹, 康 辉, 陈宜瑜. 湖湾效应对长江中游湖泊水生植被多样性的影响. 生态学报, 1996, 16 (5): 476-483.

[4] Adrian EW, Brian M, John E. Fish induced macrophyte loss in shallow lakes: top-down and bottom-up processes in microcosm experiments. Freshwater Biology, 2002, 47: 2216-2232.

[5] 张圣照, 王国祥, 兴培民. 东太湖水生植被及其沼泽化趋势. 植物资源与环境, 1999, 8 (2): 1-6.

[6] 陈开宁, 范成新, 季 江. 东太湖水环境质量调查及保护对策. 海洋湖沼通报, 1996, (1): 9-17.

[7] 金相灿，屠清瑛. 湖泊富营养化调查规范. 北京：中国环境科学出版社, 1990.

[8] Woodward FI. Climate and plant distribution. Cambridge: Cambridge University, 1987.

[9] Oke TR. Boundary layer climates, Second Edition. London and New York: Methuen, 1987. 
[10] 朱松泉, 刘正文. 伊乐藻-草鱼圈养人工复合生态系统建设的研究. 湖泊科学, 1996, 8(增刊): 46-61.

[11] Canfield DE, Jr KA, Langland SB et al. Relations between water transparency and maximum depth of macrophytes colonization in lakes. Journal of Aquatic Plant Management, 1985, 23: 25-28.

[12] Nichols SA. Depth, substrate, and turbidity relationships of some Wisconsin lake plants. Trans Wis Acad Sci, 1992, 80: 97-118.

[13] 秦伯强, 胡维平, 陈伟民. 太湖水环境演化过程与机理. 北京: 科学出版社, 2004

[14] 任 南, 严国安, 马剑敏等. 环境因子对东湖几种沉水植物生理的影响研究. 武汉大学学报(自然科学版), 1996, 42 (2): 213-217.

[15] Spencer WE, Wetzel RG, Teeri J. Photosynthetic phenotype plasticity and the role of phosphoenolpyruvate carboxylase in Hydrilla verticillata. Plant Science, 1996, 118: 1-9.

[16] Stanley RA, Naylor AW. Photosynthesis in eurasion watermilfoil (Myriophyllum spicatum.L ). Plant Physiology, 1972, 50: 149-151.

[17] Baur M, Mayer AJ, Heumann HG et al. Distribution of plasma membrane $\mathrm{H}^{+}$-ATPase and polar current patterns in leaves and stems of Elodea Canadensis. Acta Botanica, 1996, 109: 382-387.

[18] Hiedema H, Prins HBA. Coupling of proton fluxes in the polar leaves of Potamogeton lucens L. Journal of Experimental Botany, 1992, 43: 907-914.

[19] 陈 刚, 谢 田, 莫 非等. 光照、 $\mathrm{NaHCO}_{3}$ 和 $\mathrm{pH}$ 值对金鱼藻光和作用的影响. 贵州环保科技, 2004, 4: 16-19.

[20] 张 容, 杨龙元, 谷孝鸿等. 东太湖典型湖区水环境特征时空变化分析. 水利学报, 2007(增刊): 597-605.

[21] 施炜纲, 王 博, 周 昕. 蟹、鱼网围混养对草型湖泊氮磷平衡的影响. 湖泊科学, 1999, 11(4): 363-368.

[22] 吴庆龙，陈开宁，胡耀辉等. 东太湖河蟹网围养殖的环境效应. 农业环境保护. 2001, 20 (6): 432-434, 442.

[23] Scheffer M. The effect of aquatic vegetation on turbidity: how important are the filter feeders. Hydrobiologia, 1999, 408(4): 307-316.

[24] Sabine H, Elisabeth MG. Can allelopathically active submerged macrophytes stabilize clear-water states in shallow lakes? Basic and Applied Ecology, 2008, 9(4): 422-432.

[25] 金 刚, 李钟杰, 刘伙泉等. 保安湖沉水植被恢复及其渔业效益. 湖泊科学, 1999, 1(3): 260-266.

[26] 谷孝鸿, 陈开宁, 胡耀辉等. 东太湖伊乐藻的营养繁殖及对渔业污水的净化. 上海环境科学, 2002, 21(1): 43-45.

[27] 马剑敏, 严国安, 罗岳平等. 武汉东湖受控生态系统中水生植被恢复结构优化及水质动态. 湖泊科学, 1997, 9(4): $359-363$.

[28] 王 琚, 顾宇飞, 朱增银等. 不同营养状态下金鱼藻的生理响应. 应用生态学报, 2005, 16(2): 337-340.

[29] 杨清心, 李文朝. 高密度网围养鱼对水生植被的影响及生态对策探讨. 应用生态学报, 1996, 7(1): 83-88.

[30] 李文朝. 东太湖荠黄水发生原因及其防治对策探讨. 湖泊科学, 1997, 9(4): 364-368 